\title{
Urban Forest Health Monitoring: Large-Scale Assessments in the United States
}

\author{
Anne Buckelew Cumming, Daniel B. Twardus, and David J. Nowak
}

\begin{abstract}
The U.S. Department of Agriculture, Forest Service (USFS), together with state partners, developed methods to monitor urban forest structure, function, and health at a large statewide scale. Pilot studies have been established in five states using protocols based on USFS Forest Inventory and Analysis and Forest Health Monitoring program data collection standards. Variables and data analysis are described. Advantages of a large-scale monitoring study are discussed and examples of results from Wisconsin are presented. Studies in Indiana, Wisconsin, New Jersey, Tennessee, and Colorado, U.S., have shown that urban forest health monitoring data collection and analysis is feasible and can be implemented nationally.

Key Words. Forest health monitoring; forest inventory and analysis (FIA); urban forest effects model (UFORE); urban forestry, Wisconsin, U.S.
\end{abstract}

Urban forests provide a multitude of benefits to society such as cleaner air and water, recreational opportunities, aesthetics, and energy savings. Millions of dollars are spent annually to maintain them, yet relatively little is known about this important resource on a large scale. In an attempt to learn more about this resource and to aid in its management and planning, a pilot study to apply a national forest health monitoring protocol within urban areas was conducted. Based on standard U.S. Department of Agriculture, Forest Service Forest Health Monitoring (FHM) and Forest Inventory and Analysis (FIA) field sampling protocols, a national plot inventory grid was used to sample urban areas in five U.S. states.

Interest in urban forest inventories has increased over the last 20 years. Tallied street trees on index cards have been replaced by data collected on personal data assistants with data posted to web sites to allow access by multiple users. Daily management and annual work planning for municipal tree management is integrated fully with inventory data in many cities. Although cities have inventories of their tree resources, data collected are not standardized among communities; may not include tree data from all land types and ownerships; and are not available for aggregation into a regional or statewide database. Although useful for municipal management, these data cannot be used for policy analysis and planning at the state, regional, or national scales where data are needed to describe urban forest structure, function, health, and risks to pests and diseases.

Comprehensive management and planning requires accurate baseline information. Data from trees in urban areas can be used to monitor the status, conditions, and trends of the urban forest resource at large scales. This monitoring can meet the need of many programs by allowing for the assessment of:

1) Condition, composition, and extent of the urban forest resource (to aid in management and planning);

2) Changes and threats to the sustainability of urban forests (species and cover changes, invasive species, pest outbreaks);

3) Ecosystem services and values (air pollution removal, carbon storage and sequestration, building energy conservation);

4) Basic data (species composition, leaf area, leaf biomass, leaf area index; tree biomass) needed for incorporation of urban vegetation within environmental regulations such as State Implementation Plans of the Clean Air Act; Total Maximum Daily Loads and Stormwater Program for $\mathrm{Mu}-$ nicipal Separate Storm Sewer Systems of the Clean Water Act; and programs aimed at reducing greenhouse gases;

5) Biomass and economics of wood use in urban areas (board foot volume, waste wood management); and

6) Long-term change in the urban forest to:

a) Understand and manage factors that alter urban forests to help sustain long-term forest health;

b) Monitor/evaluate the effectiveness of federal and state urban trees program accomplishments; and

c) Identify critical resource needs and help direct national and state program funding.

To meet the needs of state and federal natural resource managers, a series of pilot studies was initiated to determine the usefulness and feasibility of collecting urban forest data on a large scale (Nowak et al. 2004). The FIA program is tasked by Congress to describe and characterize forests and timberlands nationally, but data are collected exclusively on lands meeting a specific definition of "forest". Areas that are at least 1 ac in size (0.4 ha), $120 \mathrm{ft}$ wide $(36.6 \mathrm{~m}), 10 \%$ stocked with trees, and have undisturbed understories are sampled annually by FIA. Although this sampling accounts for the vast majority trees nationally, there are many areas with trees that are not sampled. Urban areas are one example of an underrepresented resource in the FIA system.

The Urban FHM Pilot Program interfaces with the FIA program to test the use of existing protocols, methods, data flow, and analysis in an urban context. Working in partnership with FIA, FHM, Forest Service Urban and Community Forestry program, Forest Service Research and Development, and state forestry agencies, FIA methods were modified and variables added to the existing FIA system to meet the needs of an urban forest assessment.

\section{METHODS}

The FIA grid was used to sample plots in urban areas (one plot for every 6,000 ac [2428.2 ha]) using a panel system. In this panel system, one-fifth of all plots is measured each year such 
Table 1. General data collection variables for urban forest health monitoring.

\begin{tabular}{ll}
\hline Variable type & Purpose \\
\hline Plot description & $\begin{array}{l}\text { Location, land use, owner, and ground cover are used to describe the conditions and geographic location of the plot and to be able to } \\
\text { relocate the plot in the future }\end{array}$ \\
Tree description & $\begin{array}{l}\text { Species, diameter, and height are used to characterize the tree resource in terms of species frequency, size distribution, risk to pests } \\
\text { and diseases, and estimate carbon storage and building energy conservation } \\
\text { Crown description } \\
\text { Measurements of crown width, height, and condition are used to estimate leaf area and biomass, which in turn are used to calculate } \\
\text { leaf area index, air pollution removal, and volatile organic compound emissions }\end{array}$ \\
$\begin{array}{l}\text { Fourteen damage types have been predefined; presence of one or more of these damages may indicate a pest, disease, or abiotic stress } \\
\text { influencing tree health; coupled with species frequency and crown condition, managers will be able to summarize conditions by } \\
\text { species over land use, location, or owner }\end{array}$ \\
\hline
\end{tabular}

that all plots will be measured in 5 years. In Year 6, the cycle repeats and plots in Year 1 are remeasured. Urban forest inventory plots consist of four $24 \mathrm{ft}(7.3 \mathrm{~m})$ fixed radius subplots spaced $120 \mathrm{ft}(36.6 \mathrm{~m})$ apart. The plot layout was designed to coordinate with the plot configuration currently used by FIA and FHM for forested plots. The four subplots comprise a 0.16 acre (0.067 ha) plot. Additional details about FIA sampling procedures and plot designs can be found in Bechtold and Patterson (2005) and LaBau et al. (2007).

Boundaries of urban areas are based on data from the U.S. Census Bureau and overlaid on the FIA grid. Plots within the urban boundaries, regardless of their land use or FIA-defined "forest" status, were visited, established, and measured. For complete urban analysis, data from existing FIA forest plots in urban areas are combined with the "nonforest" plots within the urban boundary. The plots are sampled during the growing season to provide for an extended suite of ecologic data that includes a full vegetation inventory and evaluation of tree damage and crown condition and information on variables needed for analysis using the Urban Forest Effects (UFORE) Model (e.g., percent crown missing, distance and direction from buildings) (Nowak and Crane 2000).

For each plot, forest health monitoring data collection protocols (Conkling and Byers 1992; U.S. Department of Agriculture, Forest Service 2002) were used on all trees greater than or equal to 1 in $(0.4 \mathrm{~cm})$ in diameter at breast height $(\mathrm{DBH} ; 4.5 \mathrm{ft}[1.37$ $\mathrm{m}])$ on each of the four 0.042 acre $(0.017 \mathrm{ha})$ subplots. Urban forest health monitoring variables included: species, diameter, crown measures, tree damage, distance of tree to buildings, ground covers on plot, condition class, and ownership. In addition, standard data collected by FIA crews were used for analysis, which includes measurements of all trees greater than or equal to 5 inches $(12.7 \mathrm{~cm}) \mathrm{DBH}$ on four 0.042 acre $(0.017 \mathrm{ha})$ subplots and saplings between 1 and 5 inches $(2.54$ to $12.7 \mathrm{~cm})$ DBH on four 0.003 acre (0.0013 ha) microplots (U.S. Department of Agriculture, Forest Service 2003).

\section{Pilot Study Locations}

Pilot studies have been initiated in five U.S. states, beginning with Indiana in 2001, where one panel of plots was sampled using existing FIA plots and additional urban plots. In 2002 and 2003, the state of Wisconsin, established their plot system, which sampled all plots (five panels) in urban areas within 2 years. This pilot also used existing FIA plots along with new urban plots for the analysis. In New Jersey, plots were visited in 2003 and 2004 with only new urban plots being established. FIA forested plots are on schedule to be completed in 2009 for New Jersey. The analysis of urban forests in New Jersey is awaiting the completed measurements of forested FIA plots within urban areas. The New Jersey situation clarified the need for better integration with the FIA program. The pilot study expanded to two other states in 2005, Tennessee and Colorado. For these pilots, all plots within urban area (even existing FIA forested plots) are measured by the urban crews during the summer to allow for better integration of data. On all plots within urban areas, standard FIA data are collected along with addition urban forest health monitoring variables. A full panel of plots in these states will be completed in 2009 .

\section{Data Collection Variables}

The pilot studies are testing the feasibility and logistics of collecting statewide urban forest data to estimate urban forest functions, structure, value, health, and pest and disease risk potential. To achieve this end, four general types of data (Table 1)

Table 2. General plot variables for urban forest health monitoring.

\begin{tabular}{|c|c|c|}
\hline Variable & Instrument & Units \\
\hline Plot number & Field manual description & Federal Information Processing Standard (FIPS) state and county codes with additional unique numbers \\
\hline State, county & Field manual description & FIPS codes \\
\hline Crew & & Initials \\
\hline Date & Calendar & $\mathrm{dd} / \mathrm{mm} / \mathrm{yyyy}$ \\
\hline Latitude/longitude & GPS unit & NAD 83 \\
\hline Elevation & Altimeter & Feet \\
\hline Land use & Field manual description & $\begin{array}{l}\text { Cropland, pasture, idle farmland, orchard, Christmas tree plantation, residential, institutional, } \\
\text { commercial/industrial, cemetery, multifamily residential, vacant, transportation corridor, rights of way, } \\
\text { parks, golf courses, other, water }\end{array}$ \\
\hline Condition class & Field manual description & Accessible forest land, nonforest land, noncensus water, denied access, area too hazardous \\
\hline Land owner & Field manual description & $\begin{array}{l}\text { Forest Service, National Forest, National Grassland, other Forest Service, government, state government, } \\
\text { local or county government, private, corporate, unincorporated partners/clubs }\end{array}$ \\
\hline Ground cover & Field manual description & $\begin{array}{l}\text { Percent of plot covered by maintained areas, trees, shrubs, buildings, permeable ground, herbaceous, } \\
\text { water, other }\end{array}$ \\
\hline
\end{tabular}


Table 3. Urban forest health monitoring variables to describe trees.

\begin{tabular}{lll}
\hline Variable & Instrument & Units \\
\hline Tree number & Field manual description & Number \\
Tree location in plot & Field manual description & Map \\
Tree status & Field manual description & Live, dead, removal, missed live tree, missed mortality tree, no history \\
Cause of death & Field manual description & Insect, disease, fire, animal, weather, vegetation, unknown/other, human, physical \\
Species & Field guides & UFORE species codes \\
Diameter at breast height & Diameter tape & Inches \\
Height to diameter if not 4.5 & Tape measure & Feet \\
Length of tree (height) & Clinometer & Feet \\
Height to live crown & Clinometer & Feet \\
Distance from tree to buildings & Tape measure & Feet \\
\hline
\end{tabular}

UFORE = Urban Forest Effects Model.

were collected to describe plot, trees, crowns, and damages. Within each of these groupings, specific variables are collected (Tables 2-5).

\section{Data Analysis}

Data are analyzed using the UFORE Model. The UFORE model was developed to help managers and researchers quantify urban forest structure and its functions (Nowak and Crane 2000). UFORE is designed to use standardized field data from randomly located plots and local hourly air pollution and meteorologic data to quantify urban forest structure and numerous urban forest effects for cities around the world. The model has been adapted to use statewide data and general estimates for structural value (Nowak et al. 2002), air pollution removal (Nowak et al. 2006), carbon storage and sequestration (Nowak and Crane, 2002), risk to certain pests and diseases (Nowak et al. 2001), and building energy conservation (Nowak et al. 2006a, 2006b, 2006c, 2007a, 2007b).

\section{Advantages and Disadvantages of the Data Collection Approach}

The proposed national urban forest health monitoring system has been developed to meet the needs of state and federal urban resource managers for data and analysis of the structure, function, and health of the urban forest. This program, which is designed to provide data and information at the state, regional, and national scale, is not designed to provide information at the local or city scale because there will be too few plots at this scale to provide adequate estimates. Plots at the local scale can be augmented with additional plots to provide desired accuracy of data estimates. Although not readily applicable at the local scale, this national program has advantages related to state and national policies and planning, but also has limitations as outlined in Table 6.

\section{RESULTS: WISCONSIN'S URBAN FOREST}

Data from 139 field plots located within the urban areas of Wisconsin were analyzed in this pilot project conducted by the U.S. Department of Agriculture, Forest Service, in partnership with the State of Wisconsin. Urban areas were designated using the 1990 census definition (U.S. Census Bureau 2002).

Data from this statewide urban inventory has yielded interesting and useful information. Quantitative descriptions of structure, function, value, and health will assist state and federal resource managers to prioritize and target funding and staffing to maximize benefits of the urban forest for the public. The following is a summary of results from the Wisconsin pilot (Cumming et al. 2007).

\section{Structure}

A total of 80 different tree species were identified in the urban areas of Wisconsin. These species represent 31 genera and 17 plant families. They are fairly diverse with no one species comprising more than $8 \%$ of the existing population overall. The Acer and Fraxinus genera, however, combine for $30 \%$ of all trees in urban Wisconsin. Given the potential risk to Acer from the Asian longhorned beetle and Fraxinus from the emerald ash borer, urban tree planting efforts in Wisconsin should consider shifting away from these genera to other suitable genera to avoid potential large-scale losses from exotic invasive beetles that exist within the United States.

\section{Functions}

Carbon storage by Wisconsin's urban forest is estimated at 6.7 million tons (6.1 million metric tons). The species that are estimated to sequester the most carbon annually are Acer negundo (7.2\% of the total annual sequestration), Fraxinus pennsylvanica (7.1\%), and Quercus macrocarpa (5.4\%). Annual carbon sequestration by urban trees is valued at $\$ 8.1$ million per year. The

Table 4. Urban forest health monitoring variables to describe crowns.

\begin{tabular}{|c|c|c|}
\hline Variable & Instrument & Units \\
\hline Crown light exposure & Field manual description & $\begin{array}{l}\text { No full light; top or one side; top }+ \text { side or two sides; top }+ \text { two sides; top }+ \text { three sides; } \\
\text { top + four sides }\end{array}$ \\
\hline Crown position & Field manual description & Superstory, overstory, understory, open canopy, undefined \\
\hline Crown density & Field manual description & $5 \%$ classes ranging from 0 (no crown) to $100 \%$ \\
\hline Crown dieback & Field manual description & $5 \%$ classes ranging from 0 to $100 \%$ (crown dead) \\
\hline Foliage transparency & Field manual description & $5 \%$ classes ranging from 0 (full crown) to $100 \%$ (few leaves present) \\
\hline Foliage absent & Field manual description & $5 \%$ classes ranging from 0 to $100 \%$ \\
\hline Crown diameter-two directions & Tape measure & Feet \\
\hline
\end{tabular}


Table 5. Damage Descriptions for urban forest health monitoring.

\begin{tabular}{lll}
\hline Variable & Instrument & Units \\
\hline Damage_-presence & Field manual description & $\begin{array}{l}\text { Canker or decay; wound or crack; borers or bark beetles; stem-girdling roots; topping or poor pruning; } \\
\text { excessive mulch; dead or dying branches; leaf chlorosis or necrosis; evidence of defoliation; vines in } \\
\end{array}$ \\
& crown; root conflict with sidewalk; crown conflict with utility wires; improper planting \\
\hline
\end{tabular}

urban forests in Wisconsin are estimated to remove approximately 7,050 tons (6,400 metric tons) of pollution per year with an associated annual value of approximately $\$ 36.3$ million. Pollutant removal rate was greatest for ozone $\left(\mathrm{O}_{3}\right)$ followed by particulate matter less than $10 \mu \mathrm{m}$, nitrogen dioxide, sulfur dioxide, and carbon monoxide.

\section{Structural Value}

The urban forests of Wisconsin provide significant social and environmental benefits to the people of Wisconsin. In addition to the functional values described previously, the estimated structural value of Wisconsin's urban forest is approximately $\$ 17$ billion.

\section{Health}

Overall, Wisconsin's urban forests are healthy. Health indicators such as crown dieback, density, and damage reveal only a few issues of concern. Populus tremuloides showed a relatively high average dieback. Coupled with its borderline average crown density, it appears that the species is not doing very well in Wisconsin's urban forests. More investigation is needed as to whether hypoxylon canker, a common disease of $P$. tremuloides, is associated with this dieback.

\section{Potential Value Loss Resulting from Invasive Pests and Diseases}

The risk of Asian longhorned beetle to Wisconsin's urban forest is an estimated loss of $\$ 8.0$ billion in structural value or $60.2 \%$ of all urban trees in the state. The risk of gypsy moth, already present in Wisconsin, is an estimated loss of $\$ 960$ million in structural value. Finally, the emerald ash borer can kill many species of ash trees and has been detected in states adjacent to Wisconsin. The potential urban risk to this borer in Wisconsin is $\$ 2.4$ billion or $12.5 \%$ of the urban forest tree population.

\section{CONCLUSION}

Urban tree management, just like timber management that uses FIA data, is executed at the local scale (community or stand). Policy and planning decisions involving forest lands are aided by state, regional, and national databases, which are, in part, populated with data collected by the FIA/FHM programs. Similarly, wide-scale urban forest inventories and assessments should gather data at a comparable scale. Quantifying magnitude, composition, and condition of the urban forest will aid in comprehensive planning and policies. Identifying changes in species composition, cover types, and presence of invasive species will provide insight to maintain sustainable urban forest systems. Basic metrics, like canopy cover, biomass, and leaf area, can be translated into ecosystem services and values (e.g., carbon sequestration, air pollution removal) of a state's (or the nation's) urban trees.

Long-term monitoring data on rates of change in and around urban areas are critical to developing management plans to sustain urban forest health and cover at the local, regional, and national scales. Health monitoring information can be used to detect or determine what factors are leading to changes in urban forests. Thus, regional and statewide management plans can be developed to help offset the undesirable forces of change. In addition, with accurate data on rates of change, accurate plans for sustaining or enhancing forest cover can be developed. Through continual monitoring, these plans can be updated to sustain urban forest health and consequently environmental quality and human health in urban and urbanizing areas.

Comprehensive and strategic policies must be based on accurate baseline and trend data. The large-scale data generated through the methods described here will assist policy and management decisions at the regional and state levels and influence actions on a local scale. Basic data collected, like species, composition, biomass, and leaf area, will be used to incorporate urban vegetation within environmental regulations. National mandates like the Clean Air Act and the Clean Water Act are beginning to recognize the contributions of trees and vegetation to improved resource conditions. For example, state implementation plans may now include trees as a voluntary measure to improve air quality (U.S. EPA 2006). In addition, there are several other environmental programs in which urban trees could make a contribution to improving environmental quality (e.g., Total Maximum Daily Loads and Stormwater Program for Municipal Separate Storm Sewer Systems of the Clean Water Act; and several proposed climate change programs) (Nowak 2006).

Large-scale data that describe the current and changing forest condition, composition, and extent of the urban forest will aid

Table 6. Advantages and issues of concern related to the proposed method for statewide collection of urban forest inventory data.

\begin{tabular}{|c|c|}
\hline Advantages & Issues \\
\hline Large-scale monitoring of forest structure, functions, and health issues & May need plot intensification for increased precision \\
\hline Standardized data and collection protocols with national FIA/FHM program & May miss local variables of concern \\
\hline Broad picture of urban forest over state/multistate regions & Need adequate analysis staff for timely reporting of data \\
\hline Long-term data on rates and patterns of change & Long-term commitment to remeasure \\
\hline Annual updates & Only a fraction of the total plot population is measured each year \\
\hline Plot layout consistent with national plot layout in forests for comparative purposes & Forest subplot design is inefficient for urban areas \\
\hline Data collection includes variables collected in forests for comparative purposes & Some forest variables are not used in urban forest analyses \\
\hline
\end{tabular}

FIA/FHM $=$ forest inventory and analysis/forest health monitoring 
the management and planning of greenspace and urban ecosystem functions. Similarly, the ability to describe changes and threats to the urban forest are integrally linked to successful pest and disease management efforts. Recent outbreaks of emerald ash borer and Asian longhorned beetle are examples of how managers needed to have information about not only extent and condition, but also volume of wood affected. Tree removal and wood use efforts can be more precise and efficient when extent, volume, condition, and composition of the urban forest is known.

State and federal resource managers continue to hone the allocation of limited resources (money and staff) and target priority areas to sustain the urban forest resource. Long-term, largescale data on urban forests will enable agencies to incorporate these important forests into their current planning and prioritization processes and provide information and resources to help sustain urban forest health at the local to national scale.

Acknowledgments. We thank the following groups for their continued support: U.S. Department of Agriculture, Forest Service-Forest Health Monitoring Program, Forest Inventory and Analysis Program, Urban and Community Forestry Program, the Northeastern Area and the Northern Research Station; Wisconsin Department of Natural Resources; and Lumberjack RC\&D. Two anonymous reviewers offered helpful suggestions to earlier versions of the manuscript.

\section{LITERATURE CITED}

Bechtold, W.A., and P.L. Patterson (Eds.). 2005. The Enhanced Forest Inventory and Analysis Program-National Sampling Design and Estimation Procedures. Gen. Tech. Rep. SRS-80. U.S. Department of Agriculture, Forest Service, Southern Research Station, Asheville, NC. 85 pp.

Conkling, B.L., and G.E. Byers (Eds.). 1992. Forest Health Monitoring Field Methods Guide. Internal Report. U.S. Environmental Protection Agency, Las Vegas, NV.

Cumming, A.B., D.J. Nowak, D.B. Twardus, R. Hoehn, M. Mielke, and R. Rideout. 2007. Urban Forests of Wisconsin: Pilot Monitoring Project, 2002. USDA Forest Service. NA-FR-00-07.

LaBau, V.J., J.T. Bones, N.P. Kingsley, H.G. Lund, and W.B. Smith. 2007. A History of the Forest Survey in the United States: 1830-2004. FS-877. U.S. Department of Agriculture, Forest Service, Washington, DC. 82 pp.

Nowak, D.J. 2006. Institutionalizing urban forestry as a means to improve environmental quality. Urban Forestry and Urban Greening 5:93-100.

Nowak, D.J., and D.E. Crane. 2000. The urban forest effects (UFORE) model: Quantifying urban forest structure and functions, p. 714-720. In: Hansen M., and T. Burk (Eds.). Integrated Tools for Natural Resources Inventories in the 21st Century. Proceedings of the IUFRO Conference, 16-20 August 1998, Boise, ID. General Technical Report NC-212. U.S. Department of Agriculture, Forest Service, North Central Research Station, St. Paul, MN.

. 2002. Carbon storage and sequestration by urban trees in the USA. Environmental Pollution (Barking, Essex: 1987) 116:381-389.

Nowak, D.J., D.E. Crane, and J.F. Dwyer. 2002. Compensatory value of urban trees in the United States. Journal of Arboriculture 28:194-199.

Nowak, D.J., D.E. Crane, and J.C. Stevens. 2006. Air pollution removal by urban trees and shrubs in the United States. Urban Forestry and Urban Greening 4:115-123.

Nowak, D.J., R. Hoehn, D.E. Crane, J.C. Stevens, and J.T. Walton. 2006a. Assessing Urban Forest Effects and Values: Minneapolis' Urban Forest. USDA Forest Service, Northeastern Resource Bulletin, NE-166. 20 pp.

- 2006b. Assessing Urban Forest Effects and Values: Washington, DC's Urban Forest. USDA Forest Service, Northern Resource Bulletin NRS-1. Newtown Square, PA. 24 pp. 2006c. Assessing Urban Forest Effects and Values: Casper, WY's Urban Forest. USDA Forest Service, Northern Resource Bulletin NRS-4. Newtown Square, PA. 20 pp.

2007a. Assessing Urban Forest Effects and Values: Philadelphia's Urban Forest. USDA Forest Service, Northern Resource Bulletin NRS-7. Newtown Square, PA. 24 pp.

2007b. Assessing Urban Forest Effects and Values: New York City's Urban Forest. USDA Forest Service, Northern Resource Bulletin NRS-9. Newtown Square, PA. 24 pp.

Nowak, D.J., J. Pasek, R. Sequeira, D.E. Crane, and V. Mastro. 2001. Potential effect of Anoplophora glabripennis (Coleoptera: Cerambycidae) on urban trees in the United States. Journal of Economic Entomology 94:116-122.

Nowak, D.J., D.B. Twardus, R. Hoehn, M. Mielke, W. Smith, J.T. Walton, D.E. Crane, A.B. Cumming, and J.C. Stevens. 2004. Urban forest health monitoring in the United States, p. 181-187. In: Aguirre-Bravo, C., P.J. Pellicane, D.P. Burns, and S. Draggan (Eds.) 2006. Monitoring Science and Technology Symposium: Unifying Knowledge for Sustainability in the Western Hemisphere. 20-24 September 2004, Denver, CO. Proceedings RMRS-P-42CD. U.S. Department of Agriculture, Forest Service, Rocky Mountain Research Station, Fort Collins, CO. 990 pp.

U.S. Census Bureau. 2002. Differences between the 1990 census and Census 2000 urbaninzed area criteria. www.census.gov/geo/www/ua/ uac2k_90.html (accessed 5/9/08).

U.S. Department of Agriculture, Forest Service. 2002. Forest Inventory and Analysis National Core Field Guide, Volume 1: Field Data Collection and Procedures for Phase 2 Plots, Version 1.6. U.S. Department of Agriculture, Forest Service, Washington Office. Internal report. On file with: U.S. Department of Agriculture, Forest Service, Forest Inventory and Analysis, Arlington, VA.

2003. USFS Forest Inventory and Analysis National Core Field Guide, Volume I: Field Data Collection Procedures for Phase 2 Plots, Version 1.7. $201 \mathrm{pp}$.

U.S. EPA. 2006. Incorporating emerging and voluntary measures in a state implementation plan (SIP). Air Quality Strategies and Standards Division, Office of Air Quality Planning and Standards, U.S. Environmental Protection Agency, Research Triangle Park, NC. www. epa.gov/ttn/oarpg/t1/memoranda/evm_ievm_g.pdf (accessed 4/06).

\section{Anne Buckelew Cumming (corresponding author)}

Forester

USDA Forest Service, Northeastern Area

180 Canfield Street

Morgantown, WV 26505, U.S.

acumming@fs.fed.us

Daniel B. Twardus

Forest Health Group Leader

USDA Forest Service, Northeastern Area

180 Canfield Street

Morgantown, WV 26505, U.S.

dtwardus@fs.fed.us

David J. Nowak, PhD

Research Forester/Project Leader

USDA Forest Service, Northern Research Station

5 Moon Library

State University of New York, College Environmental Science and Forestry

Syracuse, NY 13210, U.S.

dnowak@fs.fed.us 
Résumé. Le Service forestier et le Département américain de l'agriculture, ensembles avec les partenaires des états, ont développé des méthodes pour suivre la structure, la fonction et la santé d'une forêt urbaine à grande échelle au sein d'un état. Des études pilotes ont été menées dans cinq états au moyens de protocoles basés sur les normes de collecte des données du programme d'Inventaire forestier, d'analyse et de suivi de la santé de la forêt du Service forestier américain. Les variables et l'analyse des données sont décrites. Les avantages d'une étude de suivi à grande échelle sont discutés et des exemples de résultats du Wisconsin sont présentés. Les études en Indiana, au Wisconsin, au New Jersey, au Tennessee et au Colorado ont montré que la collecte et l'analyse des données de suivi de la santé de la forêt urbaine étaient faisables et que ce système pouvait être implanté à l'échelle nationale.

Zusammenfassung. Das US-Land- und Forstwirtschaftsministerium entwickelt zusammen mit staatlichen Stellen Methoden zur landesweiten Beobachtung der urbanen Forststruktur, Funktion, und Gesundheit. In fünf Staaten wurden Pilotstudien basierend auf USFS-Forsterhebungen und Analysen sowie Überwachungen der Baumgesundheit. Es werden verschiedene Variablen und Datenanalysen beschrieben. Es werden die Vorteile von groß angelegten Studien diskutiert und Beispiele aus dem Staat Wisconsin präsentiert. Studien aus Indiana, Wisconsin, New Jersey, Tennessee und Colorado haben gezeigt, dass die Daten aus der Überwachung der Baumgesundheit und der Analyse verlässlich sind und national übertragbar sind.

Resumen. El Servicio Forestal del Departamento de Agricultura de los Estados Unidos (USFS, por sus siglas en inglés), junto con los patrocinadores estatales, desarrolló métodos de monitoreo de la estructura forestal urbana, función y salud a una escala amplia estatal. Los estudios piloto han sido establecidos en cinco estados usando protocolos basados en datos estándar colectados del Inventario Forestal y Programas de Análisis y Monitoreo de la Salud Forestal. Se describen los análisis de variables y de datos. Son discutidas las ventajas de un monitoreo a gran escala y se presentan ejemplos de los resultados de Wisconsin. Los estudios en Indiana, Wisconsin, New Jersey, Tennessee y Colorado, U.S. han mostrado que el monitoreo de la salud forestal urbana y el análisis de los datos es factible y pueden ser implementados nacionalmente. 